January 2016

\title{
Documenting Spatial and Temporal Information for Heritage Preservation: A Case Study of Sri Lanka
}

Chiranthi Wijesundara

University of Tsukuba, Japan, chiranthis@gmail.com

Shigeo Sugimoto

University of Tsukuba, Japan, sugimoto@slis.tsukuba.ac.jp

Bhuva Narayan

University of Technology, Sydney, bhuva.narayan@uts.edu.au

Please take a moment to share how this work helps you through this survey. Your feedback will be important as we plan further development of our repository.

Follow this and additional works at: https://ideaexchange.uakron.edu/docam

Part of the Cataloging and Metadata Commons, Digital Humanities Commons, $\underline{\text { Historic }}$ Preservation and Conservation Commons, and the Spatial Science Commons

\section{Recommended Citation}

Wijesundara, Chiranthi; Sugimoto, Shigeo; and Narayan, Bhuva (2015) "Documenting Spatial and Temporal Information for Heritage Preservation: A Case Study of Sri Lanka," Proceedings from the Document Academy: Vol. 2 : Iss. 1 , Article 5. DOI: https://doi.org/10.35492/docam/2/1/5

Available at: https://ideaexchange.uakron.edu/docam/vol2/iss1/5

This Conference Proceeding is brought to you for free and open access by University of Akron Press Managed at IdeaExchange@UAkron, the institutional repository of The University of Akron in Akron, Ohio, USA. It has been accepted for inclusion in Proceedings from the Document Academy by an authorized administrator of IdeaExchange@UAkron.For more information, please contact mjon@uakron.edu, uapress@uakron.edu. 


\section{Introduction}

Heritage properties around the world are continually under threat due to various natural and man-made circumstances, many of them unforeseen. Once a heritage property is altered or destroyed, restoring it back to its original state is very tedious and time-consuming, and sometime impossible. Therefore, as part of a preparedness approach over disasters, documenting heritage properties is crucial. With advancements in digital technologies, such documenting can be made easier. This paper proposes that with recent developments in the field of Geospatial technologies such as Geographic Information Systems (GIS) and Remote Sensing (RS), heritage preservation can be enhanced and improved by documenting spatial and temporal information (ST) in parallel to the other information. The study uses heritage sites in Sri Lanka as an example.

Spatial and temporal information is simply the information related to the spatial extension and temporal duration of a certain phenomenon. Thus, all heritage assets have their own special and temporal information. Hence, ST information is also an essential information resource compared with the other common information resources about a heritage property. In this study special emphasis is given to the local and community level heritage properties in Sri Lanka.

\section{Aims and Objectives of the Study}

The main aim of this paper is to explore how spatial and temporal or ST information can be documented effectively as part of a preparedness approach for heritage preservation in Sri Lanka. Additionally, it will also identify the condition and the challenges of documenting such ST information in the cultural heritage domain of Sri Lanka.

While documenting necessary facets such as excavation data, related bibliographic information, photographs etc., acquiring and recording the temporal features and spatial distribution of the heritage is also very important. For instance, when a certain heritage property is damaged, destroyed or completely washed away, the recreation can be done using 3D GIS visualization techniques. But, in order to do that we need previously acquired spatial information. During the civil war era in the northern part of the Sri Lanka, many local heritage properties were completely destroyed and unfortunately they had no proper documented information. Currently, Department of Archaeology in Sri Lanka is trying to relocate the site, which is a very arduous task. Nevertheless, if they had GPS locations it would help to relocate the sites more accurately. 
There are various organizations and people involved with ST information gathering but the reality is that none of them are completely effective by themselves and need integration of data from various agencies. Sometimes certain projects carry out large-scale digital mapping activities and produce some spatial information, but, after the project is completed, it is put away and the resulting data is not shared or disseminated well, and hence nobody else can reuse or value-add to this information. Sri Lanka also does not have policies or standards to document ST information accurately, which creates more complications for future access.

This study proposes a solution to document local heritage where ST information is an essential part of heritage preservation. To accomplish this task the authors are suggesting the implementation of a simple metadata schema that can be incorporated during the initial ST data acquisition process of a heritage site.

\section{Why Document a Heritage?}

Cultural Heritage Property (CHP) can have different categories. It may be tangible, intangible, cultural, natural heritage etc. Any heritage property is vulnerable to threats and alterations by unforeseen factors such as natural or human-made disasters. Natural disasters, for instance floods, wildfire, landslides, earthquakes and tsunami are some of the unavoidable disasters that cause damage to heritage assets. Apart from that, there are human activities and actions such as war and conflict, looting, improper development activities, unsustainable tourism, poor heritage site management etc. that directly or indirectly influence and destroy the heritage properties. Agreements such as The Hague Convention in 1954 (UNSECO, 1954) that was reaffirmed in 1999 are leading some of the major efforts to stop the destruction and to protect cultural properties especially during an armed conflict.

According to the department of archaeology in Sri Lanka, most local heritage properties are impacted by the human-made activities and the statistics are shown in Figure 1.

Article 2 of the Council of Europe's Convention for the Protection of the Architectural Heritage of Europe (Council of Europe, 1985) states that: "for the purpose of precise identification of the monuments, groups of buildings and sites to be protected, each party undertakes to maintain inventories, and in the event of threats to the properties concerned, to prepare appropriate documentation at the earliest opportunity". Hence, it is obvious that inventorying or documenting a heritage property should be done prior to a disaster and it is a key point in heritage preservation. 
Figure 1: Statistics on human-made destructions to local heritage properties during past few years (Department of Archaeology, 2013)

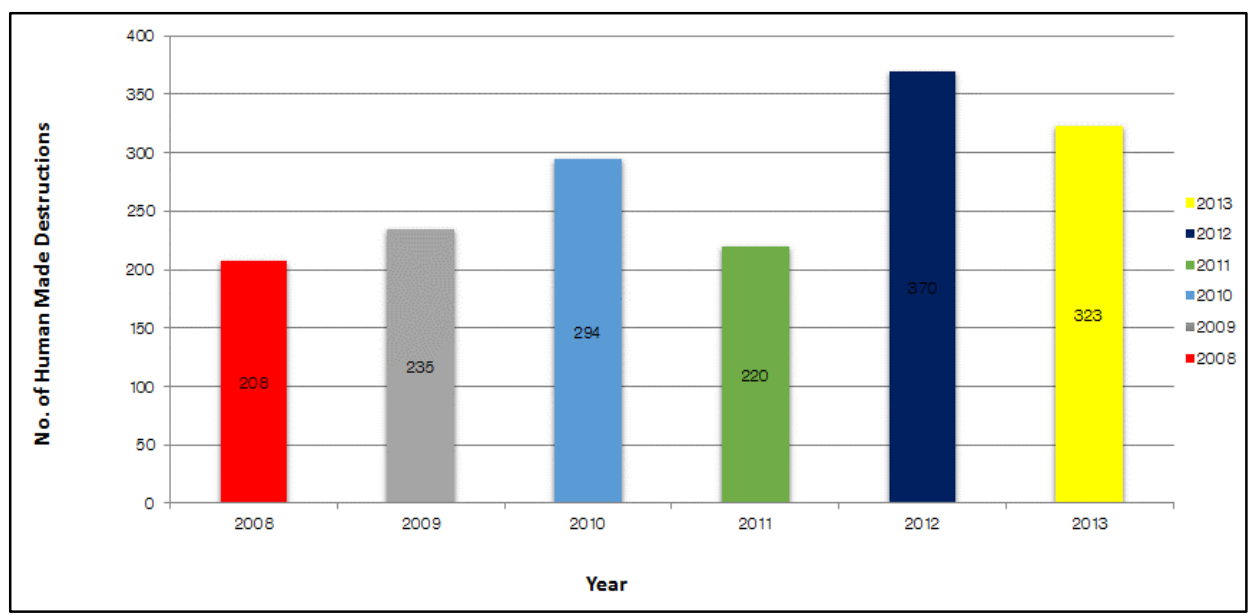

According to the Figure 2, a CHP can have multiple types of information resources and they can be documented in digital or non-digital formats. Such documentation is highly encouraged using metadata standards specially designed for heritage domain.

Figure 2: Different types of Cultural Heritage Properties (CHPs), their information resources and its connection between metadata standards

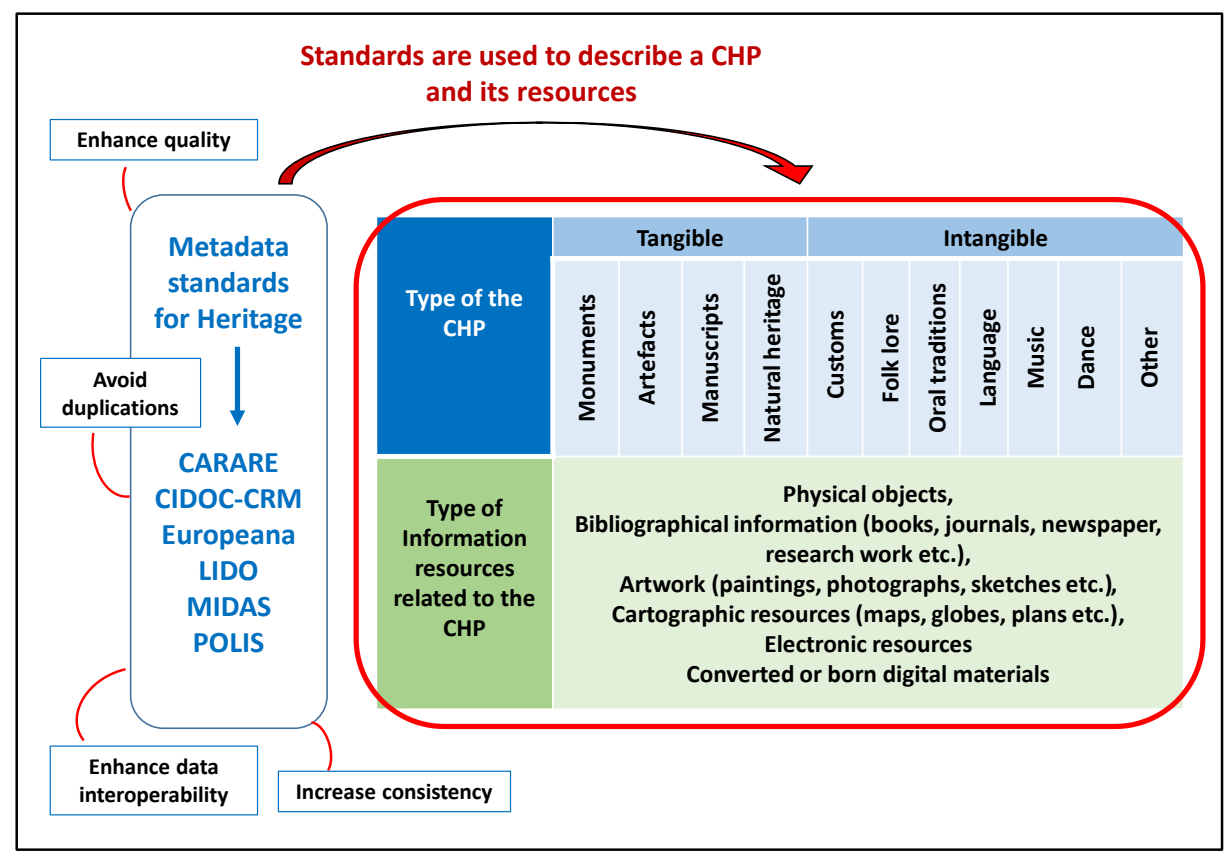


When collecting and storing any information for future access, using an accepted metadata standard is essential because it improves the quality and interoperability of the information.

\section{Heritage Preservation through ST Information}

As identified earlier heritage assets can be described using various information resources (Figure 2). A heritage property itself can be considered a physical information resource, and manuscripts or a book related to the heritage property can provide additional information also. Text, images, blueprints, models, audiovisuals or electronic formats etc., together play a part in the preservation of heritage assets. The cultural heritage sector relies also on digital information and related technologies to gather, organize, interpret, and disseminate information.

ST information is one such essential information that can be found in a heritage property. The main technology behind this is a Geospatial technology that includes Geographic Information Systems (GIS), Remote Sensing (RS) technologies and Global Positioning Systems (GPS). According to the Encyclopedia of GIS: "Geographic information is inherently spatial and temporal. Geographic applications often demand an integrative approach to examine changes and interactions over space and time" (Shekhar \& Xiong, 2008). For instance, Sigiriya (The Lion Rock) which is a well-known heritage site in Sri Lanka, has a long history. According to eminent scholar Senake Bandaranayake, the history of Sigiriya spans prehistory to $17^{\text {th }}-18^{\text {th }}$ century AD (Bandaranayake, 1999) and much of the information needed for its documentation is spread over many different sources and agencies.

Spatial information from different time periods can be easily depicted using ST technologies. During the past few decades cartographic and remotely sensed data have been recorded for Sigiriya, which can be considered as ST information on the specific site.

Figure 3 (a) shows an aerial photograph of Sigiriya acquired more than four decades ago (Survey Department of Sri Lanka, 1971), and Figure 3 (b) a sketched plan of the site in 1976 (De Silva, 1976), and Figure 3 (c) the current Google earth view of the place. Comparisons of these three images enable multi-temporal and multispatial analysis of the CHP. 
Figure 3: (a) Aerial photo of Sigiriya (Survey Department of Sri Lanka, 1971)

(b) Plan of the site in 1976 (De Silva, 1976) and

(c) Present view of the site using screenshot from Google earth (Google earth, 2015).
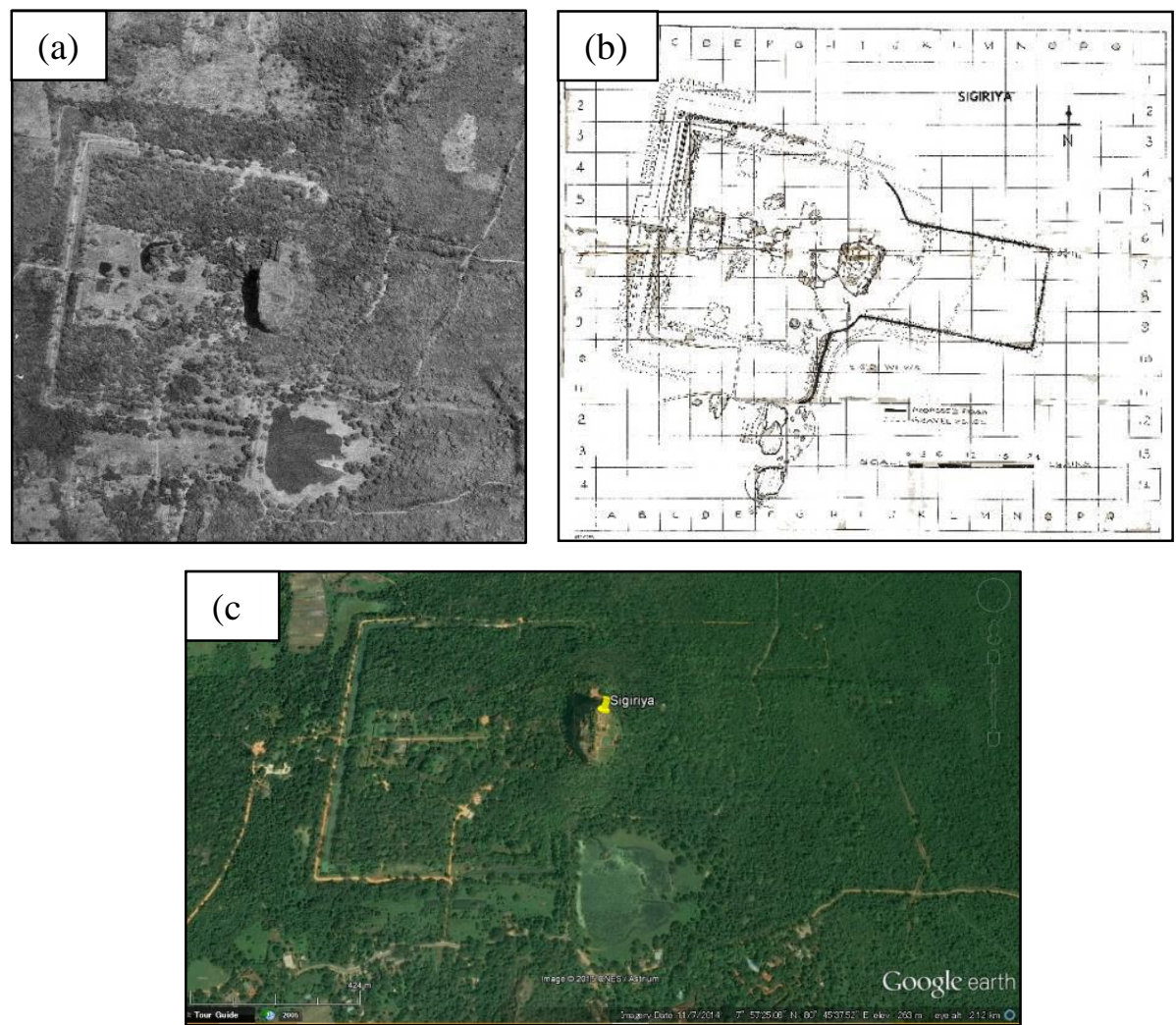

These comparisons and spatial analysis can be done using Geospatial software, and they use various mathematical calculations and overlaying techniques to perform these tasks. However, such calculations or comparisons are not easy with traditional paper-based maps or aerial photographs. Also large volumes of paper-based spatial information such as maps, aerial photos etc. create enormous problems in the long term. Accessibility, maintenance, accuracy and analysis of ST information become cumbersome when this information is non-digital. Therefore, documenting this information in digital formats is also vital.

Identification of locational information is very important especially when a heritage site is recorded for the first time. Manual surveying methods and Global Positioning Systems (GPS) both record important data, and Geospatial videography is another emerging approach that combines GPS technology and videography into one platform. This approach increases efficiency of data collection and the ability to 
survey locations over various time periods in order to analyze spatiotemporal phenomena. Furthermore, unlike present survey methods, this approach generates archival data so that places can be revisited through video (Mills, 2010).

Sometimes archaeological or heritage sites are located on very harsh terrain or in inaccessible locations. The only solution to get ST information from these places is Remotely Sensed (RS) data. RS information such as satellite images are very important when it comes to locating and analyzing prehistoric CHPs. Generally, prehistoric sites are scattered in a large area and analysis and decision making can be done more effectively using RS information (Pappu et al., 2010). In addition, prior to undertaking any regional development projects, conducting an Archaeological Impact Assessment (AIA) is very essential. If a site has enough spatial data it can be a good backup for the AIA process. Finally, GIS-related site modeling and 3D GIS approaches are also some high-level applications that can be used for heritage information and spatial-temporal data integration.

\section{Related Studies}

Heritage-related ST information is a wide arena, but in this paper the discussion is mainly on the documentation of ST information. De Roo B. et al. (2013) did a survey on GIS data standards in archaeology and the study area was France, Netherlands and Belgium. A study was conducted to identify the user perception on GIS data in archaeological context, knowledge and use of standards, what are the current recording practices of the archaeological information etc. Their findings revealed that many researchers do consider GIS as a powerful resource and a data management tool in archaeology. Nevertheless, half of the respondents did not use metadata during the data recording and did not follow proper standards while data recording and in its maintenance. In many ways, this overdependence on the technology itself, without meaningful human-added metadata only causes confusion later on. Therefore, the recommendations of their paper suggest the promoting of metadata registration and adapting GIS standards into archaeological data recording, storing, and data management processes.

Wang Shaohua and Hu Qingwu (2013) conducted a research on digitization and visualization techniques for the archaeological excavation site at the Yejia Mountain burial site in China based on multiple spatio-temporal data. Since a heritage site is often only revealed after an excavation, the proper recording of digital data throughout the process is important. Wang and Qingwu (2013) looked at multiple types of temporal and spatial data and out of that they proposed a digital visualization method for the site. The primary digital data that were used in this visualization was spatial data created during the time of excavation. They proposed 
a methodology to acquire this multiple spatial-temporal data such as high-definition remote sensing images, digital terrain models etc. through various spatial technologies. Then this data was used to generate the visualizations of the site.

Tripcevich N. \& Wernke S. (2010) did a study about the on-site recording of excavation data using mobile GIS at an excavation site in the Peruvian highlands. The paper describes a digital interface that links precise spatial provenance with digital forms and geo-referenced photographs. This system was based on ESRI ArcPad software that is mainly for mobile devices. The data-recording interface of the system contains six options: Spatial (for spatial reference information), Locus (for basic provenance information), Soils (for soil information), Collections 1, Collections 2 (for in-field inventories) and Digital Notes (for remarks). As a whole, this digital GIS-based recording system will organize data and combine precise spatial coordinates, attributes, and digital media in a single system and enables more comprehensive data registry and analysis in the field. Their study is a good example of shifting paper-based recording to digital documentation.

McKeague P. and Cowley D. (2013) in their study titled From Paper to Digital, Point to Polygon discuss how the Royal Commission on the Ancient and Historical Monuments of Scotland (RCAHMS) faced the challenge of digitizing the recording traditional map-based information and other site information collected over a number of decades. While discussing the current state of this good practice, the authors try to demonstrate challenges associated with digital spatial data for longterm practice. For instance, they discuss matters such as descriptive metadata, interoperability issues of spatial data, data standards etc. which are very important in spatial data maintenance.

Sekino Tatsuki (Sekino, 2013) developed an information system called HuTime which helps users visualize and analyze temporal information based on time series data. The basic technology behind this software is GIS technology and it uses this technology to visualize various types of data along a temporal axis. It provides chronological information along with map layers that are useful for researchers in historiography, environmental studies, health studies, etc.

In Japan, archives such as the Digital Archive of Japan's 2011 Disasters (JDA) (http://www.jdarchive.org) and National Diet Library Great East Japan Earthquake Archive (HINAGIKU) (http://kn.ndl.go.jp) also collect and maintain various other types of oral history and recorded public memory along with temporal information, spatial information and heritage information. The intention of these archives are to preserve the memories of the people affected by the Tsunami in 2011 
and this can be seen as a post-disaster effort to preserve the community memory about their heritage assets and properties.

According to Schwartz and Cook (2002) a "growing literature on social or collective memory suggests the need to look anew at the archive in the light of changes in the production and preservation of documents, in the abundance of documents, in the changing media of record, and in the nature of what is documented or who is doing the documenting, as well as the need to examine the impact of these changes, in turn, on records management and its practices, and on archives and its practices." In light of this, we concede that it is simply not enough to document the tangible aspects of heritage sites, but also the community and social aspects. Therefore, the spatiotemporal records we create and preserve are only useful up to a certain extent and do not help us understand the value of the heritage sites and the meaning they have for local communities. Nevertheless, they are an important part of the puzzle when something does go wrong, whether due to natural, or due to human-made disasters.

\section{Context and Place of Study}

The study area of this project is Sri Lanka (6 $\left.6^{\circ} 56^{\prime} 0^{\prime \prime} \mathrm{N}, 79^{\circ} 52^{\prime} 0^{\prime \prime} \mathrm{E}\right)$, an island situated in the Indian Ocean. Despite its rather small land extent, Sri Lanka (previously known as Ceylon) possess eight UNESCO world heritage sites and many other local and community level CHPs. Usually, globally recognized CHPs are well documented and well preserved. As a result, the level of documentation and availability of information on these CHPs are much higher compared to the local and community level CHPs. Well-documented information leads to a flexible recovery of a CHP during an unforeseen disaster. Unfortunately, this scenario is not true for the poorly funded and poorly documented local and community level heritage sites in Sri Lanka.

During the 2004 Tsunami disaster, one of the Sri Lankan world heritage site was damaged. The place is known as Galle Fort and this is one of the best examples of a fortified city built by Europeans (originally Portuguese) in South and South-East Asia and dates back to $16^{\text {th }}$ century (UNESCO, 2015). This place is well documented which includes a collection of temporal information such as old maps and plans of the areas dating back to $17^{\text {th }}$ century. Furthermore, Archaeological Impact Assessment (AIA) was done in the year 2007, prior to development activities of the area and this report included a sufficient amount of quality spatial and temporal information of the site (Anderson, 2007). Since it had all this 
documentation, it was fully funded and restored with the help of the International Council of Monuments and Sites (ICOMOS) and the Government of Sri Lanka.

However, poorly documented local heritage sites are now being identified and recorded by the Department of Archaeology of Sri Lanka. Primarily, the Department of Archaeology is the main government institution that plays a role in heritage sites in Sri Lanka. Recently they have established a separate GIS unit to carry out their research activities and they have started recording the spatial locations of each district separately, creating new hope for disappearing local and community level CHPs. Under this project, they mapped and relocated archaeological sites in northern Sri Lanka in the year 2013 (Jinadasa et al., 2012). The northern part of Sri Lanka was heavily disturbed by the civil war activities during the past few decades and some of the CHPs were completely demolished during that time. When the conflicts ended, the area was accessible, and now the Department of Archaeology is working on these sites. This can be seen as a postdisaster activity of recovering and relocating the demolished local CHPs, but without any documentation, it poses several challenges.

Central Environmental Authority (CEA) is the Government's main environmental protection agency in Sri Lanka. They deal with enormous spatial information and apart from natural-resource mapping they try to identify the archaeological sites of each region too. They do this work with the collaboration of the Department of Archaeology Sri Lanka and this can be recognized as a new trend of ST information collaboration in the heritage field. The Survey Department of Sri Lanka is another government organization which is responsible for the standardization and production of all Surveying and Mapping activities in Sri Lanka. They deal with all kinds of Geospatial data such as GIS maps, aerial photos, satellite photos, cartographic maps, plans etc. Recently they started a Geoportal as a stepping-stone to implement Sri Lanka Spatial Data Infrastructure (SLSDI). This organization possess some historical maps and plans of Sri Lanka and they have drawn plans for 2300 temples and shrines in Sri Lanka dating back to 1856. These plans include spatial information of national, local and community level CHPs of Sri Lanka. Since these plans were drawn in 1856 they had used the old place names of these temples and villages, which were used between 1856-1880, and is a vital temporal information for heritage researchers in Sri Lanka (Survey Department of Sri Lanka, 2015). In order to understand this information, it is also vital to preserve the records of name changes etc.

Apart from the main government organizations, a few Sri Lankan universities who teach Archaeology, such as the University of Peradeniya, University of Kelaniya, Rajarata University, and Postgraduate Institute of Archaeology of the University of 
Kelaniya conduct ST-data related archaeological investigations and join hands with various organizations and institutions. Other organizations and international institutions such as the Maritime Archaeology Unit of Sri Lanka, Central Cultural Fund of Sri Lanka/ The Netherlands Cultural Fund, Western Australian Maritime Museum, Durham University of UK etc. conducted several projects related to heritage sites in Sri Lanka which include various spatial and temporal information. They used these ST information as locational information and spatial analysis information in their studies. For example, MACHU is a European Union project to gather as much information about archaeological sites under water. They gathered information on ancient shipwrecks of EU and the rest of the world and developed an ST database, which shows map data plus temporal information for these sites. This includes around 23 shipwreck sites in Sri Lanka (MACHU, 2015).

Other than research projects, ST-related training is also a very important aspect when it comes to heritage preservation. Various universities are conducting diploma and graduate level programs to educate Geo-Information professionals. When it comes to heritage-related spatial information the MACHU Project conducted a unique training program in 2010 on the application of Geographic Information Systems in the management of underwater cultural heritage in Thailand. Members of Sri Lanka also participated in this short-term training program and this can be seen as one example of the best practice of special information training programs in the heritage arena (UNESCO Bangkok, 2010).

\section{Challenges Associated with the ST information in Sri Lankan Heritage}

Challenges of ST-related information could be categorized into various aspects such as challenges associated with economic aspects, socio-cultural perceptions, political challenges, technological challenges, institutional barriers etc. In this paper, our concern is about the key challenges related mainly to documentation and the access to the same.

Digital mapping of local CHPs in Sri Lanka is in its early stages at the moment. According to the Department of Archaeology in Sri Lanka, only around 5 out of 25 districts have finished recording the local and community level $\mathrm{CH}$ sites in their region. Since it takes more time and effort they may take few years to finish documenting the other districts and this will be a disadvantage for the local CHPs under threat. Also, currently the Department of Archaeology is only concerned with the location data of the sites. This restricts the recording to coordinates only, and this can cause long-term problems. A monument or archaeological site consists of important ST information such as timeline information related to the location, soil and geological information, land-use data, vegetation data etc. but, there is no 
mechanism to record these data at the same time of recording the location information. That means that in the future, they have to redo the same thing again and document other necessary data. Therefore, implementing a well-thought-out plan to absorb the ST information into their current documentation process is vital.

Currently, the Department of Archaeology and other organizations in Sri Lanka are not uniformly adhering to any specific heritage or spatial data documentation standards. The following example (Figure 4) shows the map attributes developed by two different departments to depict the same level of information. The Figure 4 (a) and (b) shows two map layers depicting location data related to archaeological sites in two districts of Sri Lanka (Department of Archaeology and Central Environmental Authority of Sri Lanka, personal communication, 2015).

Figure 4: (a) Map and its attribute table showing the archaeological sites in the northern province of Sri Lanka (Department of Archaeology and Central Environmental Authority, personal communication, 2015)

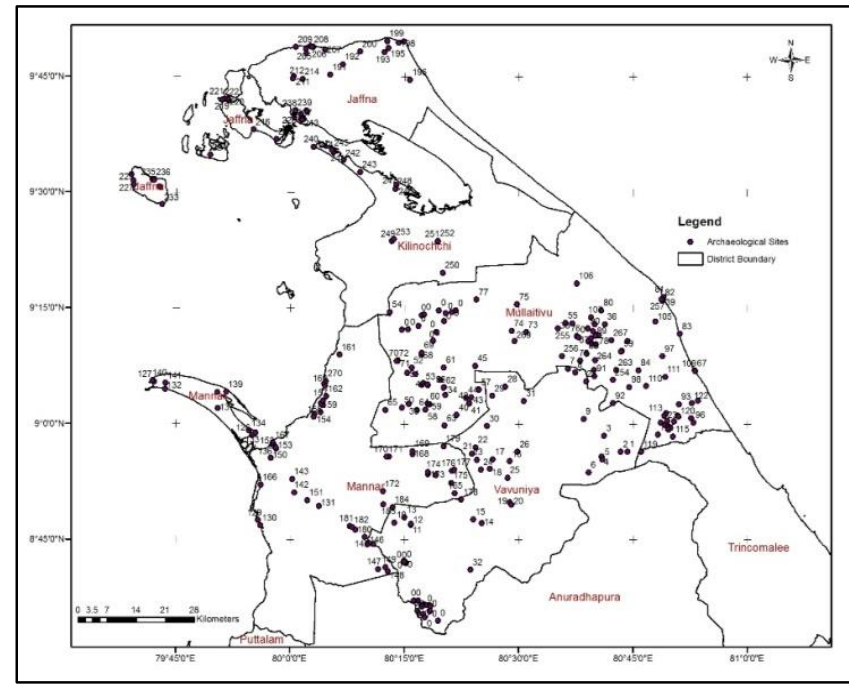

\begin{tabular}{|l|r|l|}
\hline District & OBJECTID & F7 \\
\hline Vavuniya & 1 & Nikawawa Ruins \\
\hline Vavuniya & 2 & Vedivattukallu Ruins \\
\hline Vavuniya & 3 & Kachchilamoteikulam Ruins \\
\hline Vavuniya & 4 & Vedivattukallu Ruins 02 \\
\hline Vavuniya & 5 & Vedivattakulam Ruins \\
\hline
\end{tabular}

The attribute table of figure 4 (a) created for the map layer consists only of three basic fields, and figure 4 (b) consists of eight attributes. Even though both maps represent the same level of data, the information content and standards representing the attributes are different. 
E.g. Terms such as Archaeological Site Name and Archaeological Site ID are identified differently in attribute tables.

Figure 4 (a) - Archaeological Site ID = OBJECTID Archaeological Site Name = F7

Figure 4 (b) - Archaeological Site ID = Id Archaeological Site Name $=$ Arc_Site

Figure 4: (b) Map and its attribute table showing the archaeological sites in the Kandy district of Sri Lanka (Department of Archaeology and Central Environmental Authority, personal communication, 2015)

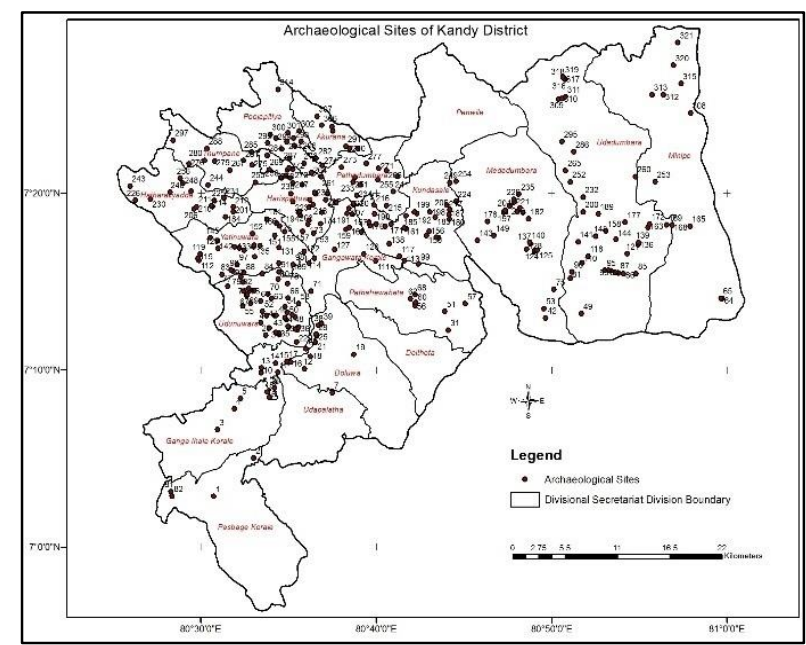

\begin{tabular}{|c|c|c|c|c|c|c|c|}
\hline Village & $\mathbf{E}$ & $\mathbf{N}$ & DSD & Id & Arc_Site & Monument & District \\
\hline Rambukpitiya & 446120.508554 & 779062.818211 & $\begin{array}{l}\text { Pasbage } \\
\text { Korale }\end{array}$ & 1 & $\begin{array}{l}\text { Rambukpitiya } \\
\text { Ratawan } \\
\text { Devalaya }\end{array}$ & Devalaya & Kandy \\
\hline Pallegama & 450298.497618 & 783052.524057 & $\begin{array}{l}\text { Pasbage } \\
\text { Korale }\end{array}$ & 2 & $\begin{array}{l}\text { Savandarapitiye } \\
\text { Paththini } \\
\text { Devalaya }\end{array}$ & Devalaya & Kandy \\
\hline Udahenthenna & 446499.905591 & 786002.608617 & $\begin{array}{l}\text { Ganga Ihala } \\
\text { Korale }\end{array}$ & 3 & $\begin{array}{l}\text { Pattini } \\
\text { Devalaya }\end{array}$ & Devalaya & Kandy \\
\hline
\end{tabular}

Not having a standard vocabulary or term when defining the attributes of spatial data creates long-term problems such as confusion of terms and difficulties of data interoperability etc. Here in this study, our main concern is to propose an initial standard to solve the above problem.

Moreover, there is no timeline data that can to be linked to the spatial data through proper standards in order for the information to be meaningful. 
Many institutions and individuals conduct heritage-related spatial information studies, but the information is not shared or interoperable. Most of the time after a project or a research activity is completed, the spatial data just stagnates and is not reused or value added. Sri Lankan Spatial Data Infrastructure (SDI) development is still in its basic level and when it is completed the Department of Archaeology needs to implement a mechanism to share their GIS data. This enables sharing of information with different levels of restrictions and it may also reduce data redundancy. However, the collaboration and information sharing between the Department of Archaeology and other institutions are still in their early stages. For the future development of cultural heritage sector and heritage preservation, this collaboration between institutions and experts from various agencies is essential.

Peoples' perceptions are another major challenge. Many organizations do not want to share their data and they do not trust other external organizations with their data. These rigid policies create various problems and slow down the efforts at preservation preparation. Apart from the above barriers, lack of training in specific fields, scarcity of resources such as machinery and expertise, high cost of spatial data, lack of proper polices, lack of interoperability, and lack of cooperation etc. are some of other common problems associated with ST information in Sri Lanka.

\section{Proposed Solution}

Sri Lanka needs some kind of standard that can be applied from the beginning to the end of the ST information management process. Figure 5 shows basic levels of ST information processes, and here the main concern is only on ST information acquisition.

Figure 5: Process of ST information in heritage arena

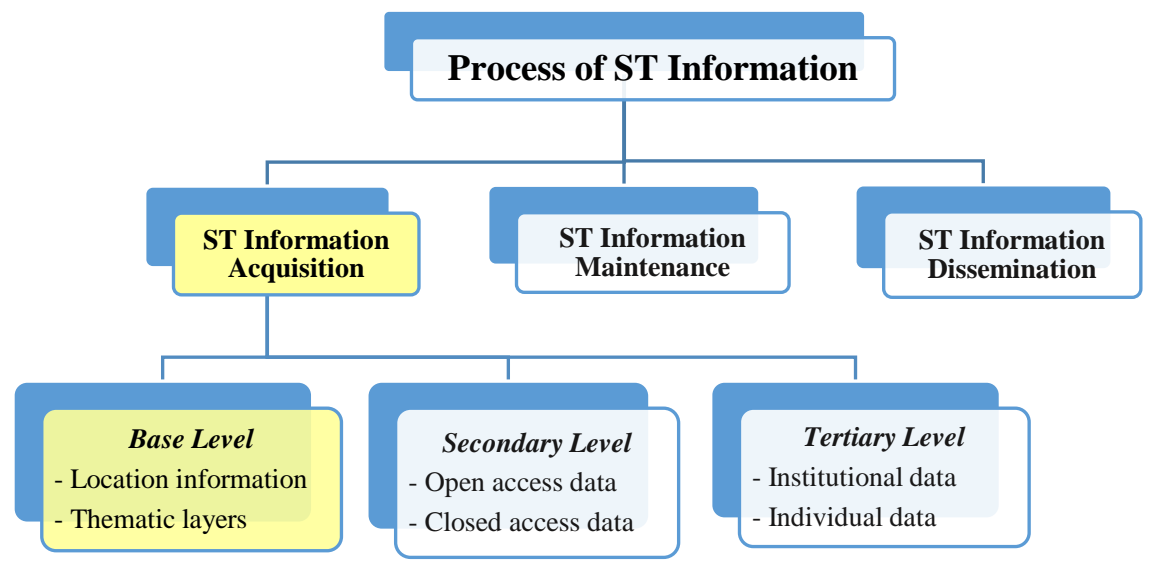


ST information acquisition can have different levels. The ST information can be obtained on-site as basic or primary level data, from open or closed-access information or as tertiary-level information from institutions or individuals.

As a starting point here we are trying to find a suitable standardized method to obtain Base Level ST information. A data standard is a list of what information should be recorded and how it should be recorded to meet a particular objective. We suggest MIDAS Heritage, developed by the Forum on Information Standards in Heritage (FISH) UK, as a suitable standard for ST information acquisition process.

MIDAS Heritage is a data standard to record historic monuments to support effective sharing and long-term preservation of knowledge of the historic environment. The specialty of MIDAS is that it is a freely available common framework that is easily adaptable to Sri Lanka's heritage environment.

Figure 6: Six themes of the MIDAS Heritage and ST themes with their mandatory attributes (MIDAS, 2012).

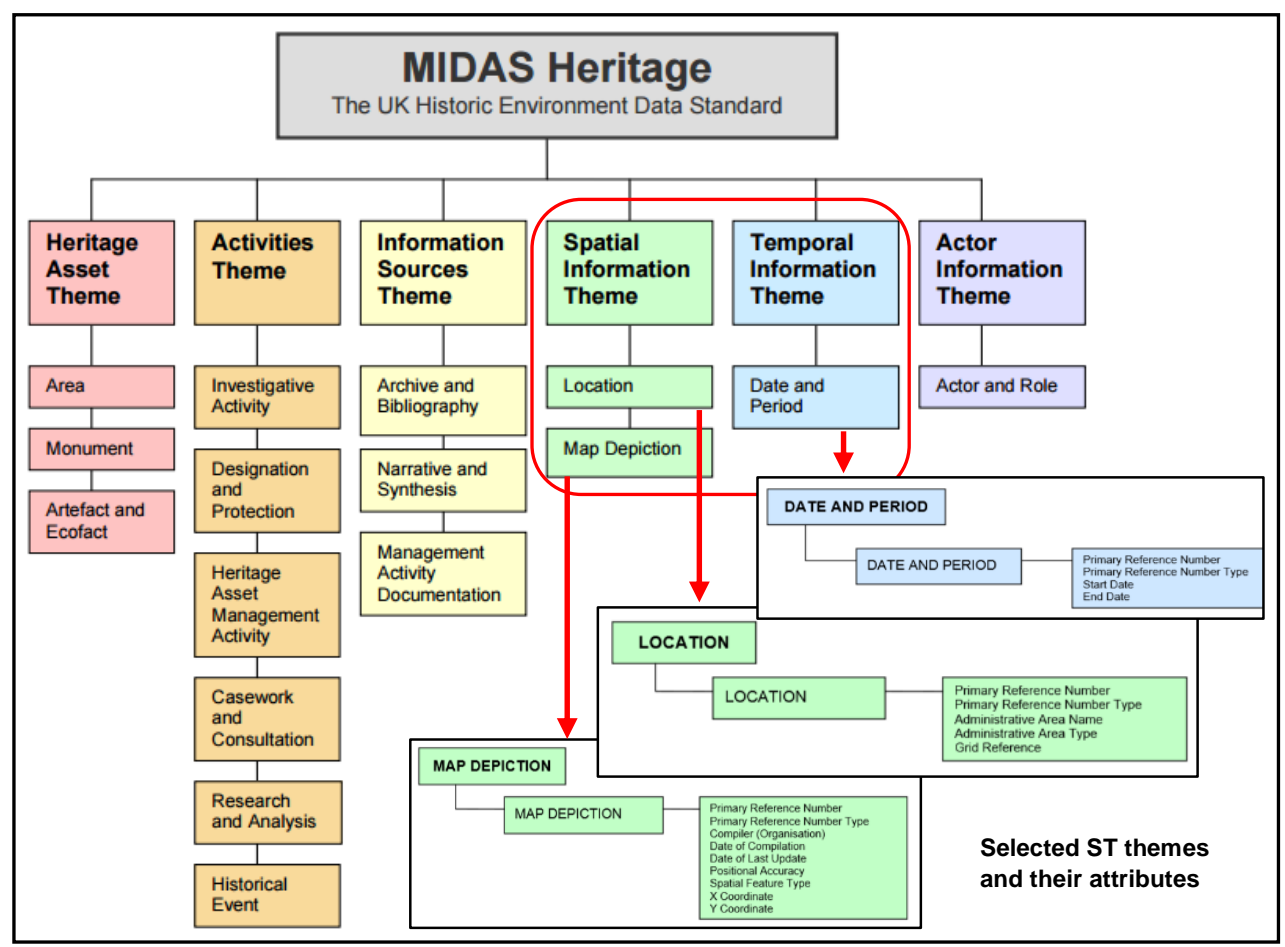


Besides, MIDAS incorporates several other standards such as SPECTRUM (for artifacts), UK Gemini Discovery Metadata Standard (for GIS data), CIDOC Conceptual Reference Model (for concepts and relationships) and FISH Interoperability Toolkit to assist sharing of information between information systems (MIDAS, 2012). MIDAS has six information themes that can be used to describe a CHP (Figure 6). Since our discussion here is limited to ST information, only the Spatial and Temporal themes are taken into consideration.

These two themes can be used to describe ST data of a CHP at the time of documenting a site. In the MIDAS guideline, they describe all the Mandatory and Optional attributes, but here the discussion is only on the Mandatory Attributes. The attributes of each theme were changed and some attributes were newly added according to the study area and according to the usefulness of data. Some attribute names were selected according to reliable online vocabularies and terms selected that best suit the Sri Lankan environment.

The adapted new ST Metadata standard for ST information acquisition in CHP can be seen below using an Entity Relationship Diagram (Figure 7).

Figure 7: ER diagram showing the relationships and attributes of the adapted standard

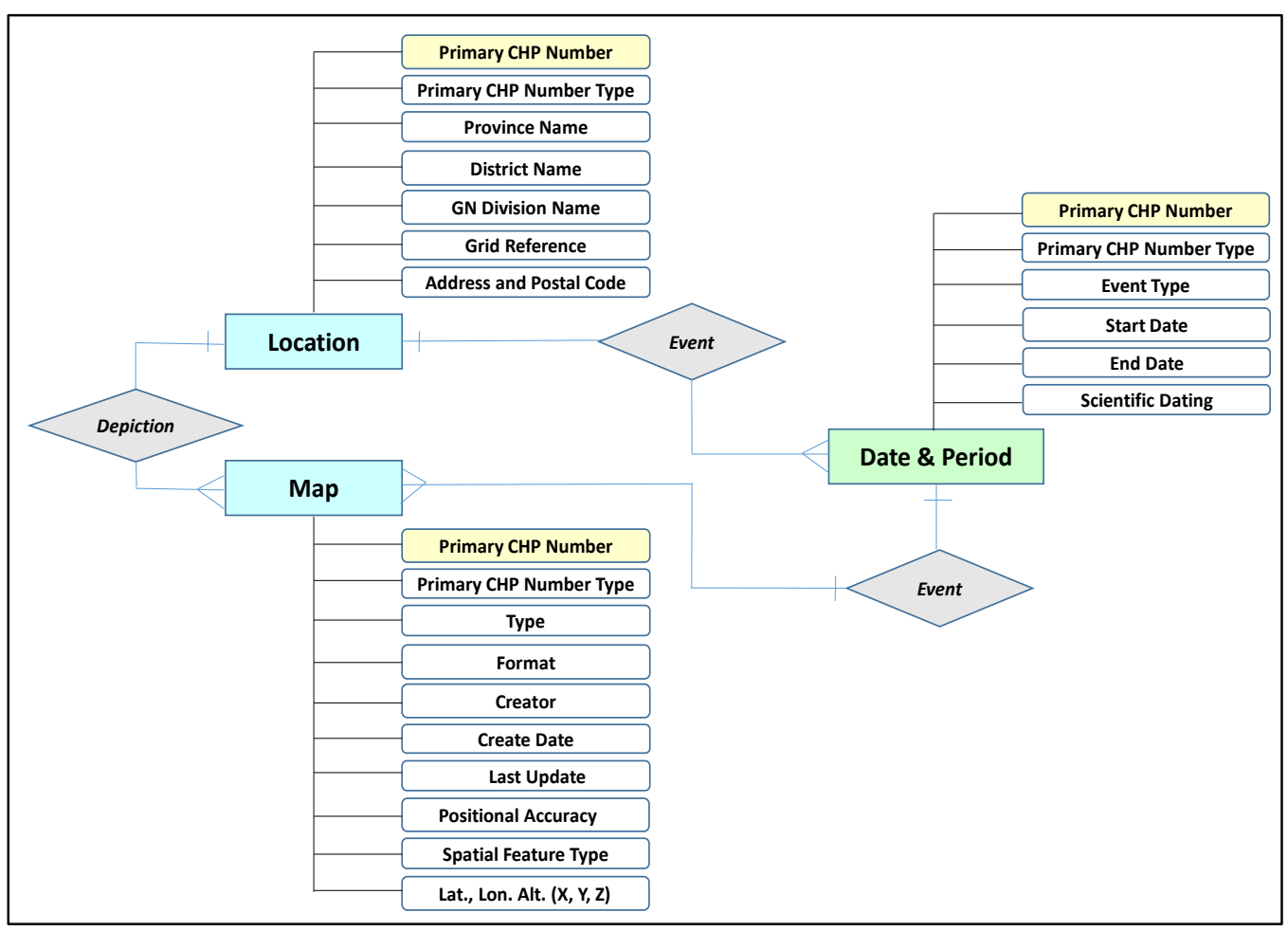


The 'Location' and 'Map' elements mainly represent the Spatial component while 'Date and Time' represents the Temporal component. Each theme attributes were carefully selected according to commonly used standard vocabularies. In addition, new attributes were added to this scheme for future use.

E.g. 'Province Name' or 'District Name' in the Location theme was adapted from 'Administrative Area Name' in the original MIDAS version.

E.g. In the original MIDAS standard in the Map Depiction theme, 'Format', 'Type', 'Creator' details are not included. In addition, in the Date and Time themes, 'Event Type' is not found and term 'Scientific Dating' is listed as an optional field. When it comes to temporal information documenting 'Event Type' it is very crucial, and so is included as a mandatory attribute in the above scheme.

When recording ST data of a CHP this metadata schema can be incorporated as a basic standard. This is only a foundation for the good practice of ST data acquisition phase in the heritage preservation arena. Since this schema should be an understandable and usable one for the ST data creators it was designed with basic mandatory fields only.

In the future, the same standard can be expanded for other ST information phases such as ST Data Maintenance and Dissemination (Figure 5) as well. Practical usage and user satisfaction of this schema when acquiring ST information in CHOs will be another direction of this study. In addition, the challenge of long-term preserving of ST information and its metadata related to heritage information is another important crossroad which can be investigated in future.

\section{Conclusion}

This paper discussed the current challenges and issues in the area of heritage preservation in Sri Lanka including the lack of standardized metadata standards in the documentation of spatial and temporal information. The paper also proposed a customized MIDAS Heritage standard for Sri Lanka based on a universal standard developed in the UK that is interoperable with other standards globally. In order for the heritage documentation currently being undertaken by the Sri Lankan government and other organizations to be useful in the future, it is essential that such a standard be adopted by all agencies involved with cultural heritage monuments in Sri Lanka. 


\section{References}

Anderson, R., Green, J., \& Souter, C. (2007). Galle Harbour Maritime Archaeological Impact Assessment Report for Sri Lankan Department of Archaeology, Department of Maritime Archaeology, Western Australian Museum, No. 235. Retrieved October 17, 2015 from http://museum.wa.gov.au/maritime-archaeology-db/maritime-reports/galle-harbourmaritime-archaeological-impact-assessment-report-sri-lankan-departmen (Archived by WebCite ${ }^{\circledR}$ at http://www.webcitation.org/6cLTevhlg)

Bandaranayake, S. (1999). Sigiriya: city, palace, and royal gardens. Central Cultural Fund, Ministry of Cultural Affairs, Sri Lanka.

Council of Europe (1985). Convention for the Protection of the Architectural Heritage of Europe, Granada, 3.X.3 October 1985. Retrieved October 17, 2015 from http://conventions.coe.int/Treaty/EN/Treaties/Html/121.htm (Archived by WebCite ${ }^{\circledR}$ at http://www.webcitation.org/6cLUMqIj6)

De Roo, B., Bourgeois, J., \& De Maeyer, P. (2013). A survey on the use of GIS and data standards in archaeology. International Journal of Heritage in the Digital Era, 2(4), 491-508.

De Silva, R. H. (1976). Archaeological Guide to Sigiriya. Colombo, Department of Archaeology, Sri Lanka.

Department of Archaeology. (2013). Statistics on Destructions to Archeological Properties during 2008 to 2013 [graph]. Exploration and Documentation Division. Department of Archaeology, Sri Lanka.

Jinadasa, U. et al. (2012). Recently Discovered Archaeological Sites Showing Evidence of Buddhism in Mullaitivu District in Northern Sri Lanka: A Study Using Geo-Informatics Tools. Conference Proceedings on SAARC International Conference on ARCHAEOLOGY OF BUDDHISM: Recent Discoveries in South Asia. SAARC Cultural Centre, Sri Lanka.

MACHU. (2015). MACHU: Managing Cultural Heritage Underwater Project 2006-2009. Retrieved October 17, 2015 from http://www.machuproject.eu/gis.htm (Archived by WebCite ${ }^{\circledR}$ at http://www.webcitation.org/6cLVQ9ABc)

McKeague, P., \& Cowley, D. (2013). From Paper to Digital, and Point to Polygon: the Application of GIS in a National Body of Survey and Record. International Journal of Heritage in the Digital Era, 2(4), 677-694.

MIDAS Heritage. (2012). The UK Historic Environment Data Standard. Version 1.1. FISH, UK. Retrieved October 17, 2015 from https://historicengland.org.uk/imagesbooks/publications/midas-heritage/ (Archived by WebCite at http://www.webcitation.org/6cLWEMM7I)

Mills, J. W., Curtis, A., Kennedy, B., Kennedy, S. W., \& Edwards, J. D. (2010). Geospatial video for field data collection. Applied Geography, 4(30), 533-547.

Pappu, S., Akhilesh, K., Ravindranath, S., \& Raj, U. (2010). Applications of satellite remote sensing for research and heritage management in Indian prehistory. Journal of Archaeological Science, 37(9), 2316-2331.

Schwartz, J., and Cook, T. (2002). Archives, Records, and Power: The Making of Modern Memory, Archival Science 2: 1-19.

Scianna, A., \& Villa, B. (2011). GIS applications in archaeology. Archeologia e Calcolatori, 22, $337-363$.

Sekino, T. (2013) Time Information System HuTime and Realization of "Temporal Information Science". PNC Annual Conference 2013, New Paradigms on Humanities Computing. Kyoto University. $\quad$ Retrieved October $\quad 17, \quad 2015$ from http://www.hutime.jp/documents/documents/PNC2013_sekino.pdf (Archived by WebCite® at http://www.webcitation.org/6cLWujoTC) 
Shekhar, S., \& Xiong, H. (2008). Encyclopedia of GIS. Springer Science \& Business Media.

Google earth. (2015). Sigiriya, [map]. 7 57'25.08" N, 80 45'37.52" E. November 07, 2014. Retrieved November 19, 2015 from http://www.earth.google.com

Survey Department of Sri Lanka. (1971). Polonnaruwa [aerial photo]. 1:25000. 1" sheet 30. Photo 91. Reel 15. Survey Department, Sri Lanka.

Survey Department Sri Lanka. (2015). Temple Tital Plans. Retrieved October 17, 2015 from http://www.survey.gov.lk/surveyweb/Home\%20English/Pdf\%20Filies/temple\%20tp\%20to \%20web.pdf (Archived by WebCite ${ }^{\circledR}$ at http://www.webcitation.org/6cLXGKwhq)

Tripcevich, N., \& Wernke, S. A. (2010). On-site recording of excavation data using mobile GIS. Journal of Field Archaeology, 35(4), 380-397.

UNESCO (1954). Hague Convention on Cultural Property 14 May 1954. Hague, Netherlands. Retrieved October 17, 2015 from http://www.unesco.org/new/en/culture/themes/armedconflict-and-heritage/the-hague-convention/text-of-the-convention-and-its-1 stprotocol/\#c284179 (Archived by WebCite ${ }^{\circledR}$ at http://www.webcitation.org/6cLV8MeC3)

UNESCO Bangkok. (2010). Underwater Cultural Heritage. Retrieved October 17, 2015 from http://www.unescobkk.org/culture/uch/capacity-building/courses/advanced/gis/ (Archived by WebCite ${ }^{\circledR}$ at http://www.webcitation.org/6cLXv0Lx8)

UNESCO. (2015). UNESCO World Heritage Convention. Old Town of Galle and its Fortifications. Retrieved October 17, 2015 from http://whc.unesco.org/en/list/451/ (Archived by WebCite ${ }^{\circledR}$ at http://www.webcitation.org/6cLXc7Vow)

Wang, S., and Hu Q. (2013). Research on Digitisation and visualisation Techniques for Archaeological Site Excavation based on Multiple Tempo-Spatial Data. Sustainable Documentation in Archaeology. Technological Perspectives in Excavation and Processing. Xi'an, China. 43-50, Retrieved October 17, 2015 from http://web.rgzm.de/fileadmin/Gruppen/Verlag/PDF-

Dateien/China_Publikation/Sustainable\%20Documentation\%20in\%20Archaeology_2014.p df (Archived by WebCite ${ }^{\circledR}$ at http://www.webcitation.org/6cLWUX9I3) 